Revista Iberoamericana, Vol. LXXV, Núm. 227, Abril-Junio 2009, 333-347

\title{
ETNOLOGÍA FICCIONAL. \\ BRUJOS, ZOMBIS Y OTROS CUENTOS CARIBEÑOS
}

\author{
POR \\ PaOla CoRTÉs-RoccA \\ San Francisco State University
}

\section{FiCCIONES CIENTÍFICAS}

En 1940, la revista The Weekly Magazine publica un artículo periodístico firmado por Inez Wallace y titulado “IWalked with a Zombie”. ${ }^{1}$ Utilizando la voz de la cronista que investiga e intenta ofrecer información, Wallace se propone confrontar a todos aquellos que -como antes le había ocurrido a ella misma- escuchan las historias sobre zombies con una sonrisa de incredulidad. "I Walked with a Zombie" es un artículo periodístico, una investigación sostenida en la lectura y en la recolección de testimonios y, fundamentalmente, un texto argumentativo que se propone demostrar que "the weird legend of the zombie is more than a legend" (Wallace 96). El artículo es, además, una crónica de viaje, no sólo en tanto da cuenta del desplazamiento de la cronista sino en tanto propone o refuerza diferencias territoriales y culturales ya existentes y explica, a los que están acá, lo que ocurre allá. Lo que está acá es “our highly civilized United States” y desde acá se origina el viaje de la cronista hacia allá, hacia el territorio del misterio y de la magia que es Haití. Es también acá, donde está la escritura y la lectura sobre ese espacio - "I have read of zombies in more books than one”, aclara la cronista-; es también acá donde se consignan los relatos de las "indisputable sources": "weird tales from the lips of white men and women whose word I could not doubt”, palabras blancas que explicarán las acciones mágicas y misteriosas de los negros.

Si bien el artículo de Wallace pertenece al género de crónicas que se publican en los medios masivos, el texto ensaya todos los gestos del protocolo etnológico que hunde sus raíces en el siglo xix: un yo que está acá, del lado de la civilización,

1 Desde 1911 y hasta la década del 60, la Hearst Corporation publica The American Weekly, una revista que se incluye como suplemento en el diario del domingo. Una suerte de precursora de National Enquirer, The American Weekly tenía aproximadamente 50.000.000 de lectores y presentaba historias de muerte y suspenso acompañadas de imágenes e ilustraciones de corte sensacionalista. El artículo de Inez Wallace fue tomado dos o tres años más tarde por como base del guión de la película de Jacques Tourneur que lleva el mismo título. 
el saber y la escritura y que desde ahí se sostiene en la observación de campo y los testimonios autorizados para dar cuenta de un otro signado por la pura diferencia, una diferencia que básicamente tiene que ver con la negación de la racionalidad occidental y que se hunde en el terreno de la magia y las prácticas exóticas. Publicado a principios de la década del 40, el artículo de Wallace puede leerse como el reverso exacto de lo que constituye el programa de la vanguardia negrista en el Caribe, como contrapunto de, por ejemplo, Los cuentos negros de Cuba, que Lydia Cabrera publica en la misma época, primero en París y luego en La Habana.

Publicado en 1936 por la editorial Gallimard, el libro de Cabrera señala ya desde su título -Contes nègres de Cuba-que se trata de una ficción. Son cuentos publicados primero en revistas literarias francesas como Le Nouvelles Littéraires o Cahiers du Sur. La edición en castellano, realizada cuatro años más tarde en Cuba, incluye un prólogo firmado por Fernando Ortiz, el autor de Los negros brujos. Ortiz prologa el libro del Cabrera, del mismo modo que Césare Lombroso había prologado el suyo. La firma de ambos prologuistas -la de Lombroso en Los negros brujos y la de Ortiz en Los cuentos negros de Cuba-señala la pertenencia de ambos textos a un campo específico. Con su prólogo, Lombroso celebra y autoriza el ingreso de Ortiz al campo de la criminología; Ortiz hace exactamente lo contrario con el texto de Cabrera. El prólogo y la firma de Ortiz están allí para garantizar que los relatos de Cabrera deben quedarse en el terreno de la literatura. "Lydia Cabrera fue penetrando el bosque de las leyendas negras de La Habana por simple curiosidad y luego por deleite", dice Ortiz y agrega, "al fin fue transcribiéndolas y coleccionándolas” (31). Ortiz garantiza que lo que leeremos a continuación son leyendas negras, mitos producidos por la cultura negra cubana, ficciones que Lydia Cabrera transcribe y colecciona. La frase es el contrapunto exacto de lo que abre el artículo de Wallace, destinado a probar que la leyenda del zombi es más que una leyenda, precisamente porque no es una leyenda, porque no se trata de una ficción folklórica ni literaria, sino de un hecho periodístico. Para remarcar el carácter ficcional de los textos de Cabrera y al mismo tiempo señalar su valor etnológico, Ortiz se dedica a aclarar el lugar de Cabrera en relación con lo que se leerá a continuación: Cabrera es alguien que colecciona y transcribe, y no una autora que crea o inventa relatos. Al desligar a Cabrera de los modos en que históricamente se percibe al autor literario, Los cuentos negros de Cuba son, según explica el prologuista, el resultado de una "colaboración, la del folklore negro y su traductora blanca” (32). La comparación esclarece también el lugar de Wallace: ella no produce un relato literario, tampoco traduce ni colecciona ni trascribe leyendas haitianas. Publicado su artículo en una revista periodística de difusión masiva, Wallace es una suerte de periodista y etnógrafa que expone la existencia de los zombies, allí donde la desinformación proponía una leyenda. 
Tal vez sea legítimo cuestionar esta comparación: efectivamente pareciera que no tiene mucho sentido confrontar a una reconocida artista de vanguardia como Lydia Cabrera con una ignota firma de una revista masiva, cuyas tapas presentaban ilustraciones exóticas acompañando notas como "Our Cavemen Ancestors", “The Treasure Hunters”, o sensacionalistas y romanticonas como "Challenge to Happiness”, “Dead Man Passport”. Sin embargo, si reúno y pongo a dialogar estos textos no es porque declaro en suspenso la diferencia de valor estético, cultural y político o porque pretendo desconocer la especificidad de la literatura y el murmullo de los medios. Reúno y confronto estos textos porque, sin ignorar su radical diferencia, creo que pueden leerse como ecos de esa gran caja de resonancia que fue, a fines del siglo xIx y principios del siglo xx, el encuentro entre el discurso médico y el discurso legal. Ese encuentro llamado criminología reunió a medicina, psiquiatría, sociología, etnología y otros saberes de las ciencias sociales alrededor del discurso, las prácticas y las instituciones dedicadas a la administración de la ley. En el marco del pensamiento positivista imperante en el siglo xıx y a partir de los trabajos desarrollados por Césare Lombroso, Gabriel Tarde y Alexandre Lacassagne, la criminología produce un poderoso campo epistemológico en Latinoamérica, a partir de los trabajos de Miguel Macedo y Julio Guerrero en México, José María Ramos Mejía y José Ingenieros en Argentina, Octavio Beche en Costa Rica, Clovis Bevilacqua y Afraino Peixoto en Brasil y el mismo Fernando Ortiz en Cuba.

La hegemonía del discurso criminológico implica un nuevo modo de pensar la relación entre otredad, ley y castigo. Si el iluminismo postulaba un sujeto de la voluntad y la razón capaz de obedecer la ley, la criminología propondrá un nuevo criterio de transgresión a las normas, vinculado a causas hereditarias, físicas y ambientales. Organizada alrededor de las categorías de identificación, higiene social y gobernabilidad, la criminología postulará la necesidad de estudiar y vigilar al otro, conceptualizado como un "virus" o un elemento enfermo del cuerpo social. En este sentido, el discurso criminológico será totalmente funcional a los proyectos de fundación y modernización de los estados nacionales en Latinoamérica, porque brinda el vocabulario médico con el que establecer los modos de participación en la vida política. La criminología ocupa un lugar central en el proceso de constitución y modernización del estado porque constituye una utopía política: sin violencia y sin coerción, entrega las herramientas científicas con las que distinguir entre la normalidad y la patología, entre el ciudadano y el que queda fuera de la nación, y también propone métodos para anticipar enfermedades sociales y curarlas.

De este modo, todo texto criminológico es, simultáneamente, un tratado político-legal y un ensayo médico y etnológico. Se trata de estudiar las diferencias -de clase, de género, de raza- con el protocolo de la etnología y con el vocabulario de la medicina. Por eso, los textos de Cabrera y de Wallace constituyen dos modos 
de responder, casi medio siglo después, a la hegemonía del discurso criminológico. Se trata de textos que producen diferentes instancias de enunciación, circulan en espacios distintos y proponen relaciones opuestas entre ficción y verdad. Se trata de dos piezas que hacen máquina con el mecanismo criminológico, lo releen y reformulan.

\section{Cuerpos Fuera DE LUGAR}

En el contexto de la reciente independencia de Cuba, el tratado etnológico de Ortiz, Los negros brujos (1906), constituye una genealogía racial y un programa acerca de cómo resolver las tensiones entre las diferentes razas y culturas que definen la identidad caribeña. Ortiz se propone allí estudiar la cultura afrocubana, "sus supersticiones, sus organizaciones, sus lenguajes, sus danzas" (19). Como un buen etnólogo, Ortiz dedica los capítulos titulados “La brujería” y "Los brujos” al análisis de los dioses, la triple función del brujo-como sacerdote, médico y agorero-, la clasificación de las divinidades y sus formas de adoración, pero también a la jerga y los rituales, la vestimenta y la música, rastreando sus orígenes africanos y su transformación en el contexto cubano. En su inflexión etnológica, Los negros brujos contextualiza e historiza la práctica de la brujería, que considera un elemento central para la comprensión de la cultura afrocubana. Al enunciar desde el típico lugar del letrado, el etnólogo desempeña la función de mediador y traductor, de vínculo entre dos culturas.

En un intento por desarticular los mecanismos de legitimación de la violencia racial y de la exclusión política, la etnología de Ortiz no observa "la falta de moralidad sino una moralidad distinta y unas valoraciones sociales diversas, impuestas a la conciencia de los negros africanos por sus circunstancias, diferentes de las de los blancos, tocante a sus condiciones económicas políticas y culturales" ("Prólogo" 32). Así, si las hipótesis etnológicas cuestionan la atribución "natural” de valores y jerarquías para proponer una política paternalista que apuesta por la hibridez, el vocabulario médico liga la cultura negra con la criminalidad y con las "capas cancerosas" de la sociedad.

Con Los negros brujos, Fernando Ortiz no sólo propone la categoría de hibridación que desempeñará un rol central en los modos de pensar la relación entre raza e identidad latinoamericana durante el siglo xx; además escribe un tratado que nos dice que la criminología es, ya de por sí, un discurso híbrido, entre la etnología y la medicina, entre las hipótesis científicas y las legislaciones sociales. Publicados cuatro décadas más tarde, los textos de Cabrera y de Wallace constituyen la puesta en escena más explícita de los límites del discurso etnológico: la diferente moralidad y las diferentes valoraciones dejan de ser tales cuando aparece la ficción que desarma 
la verdad científica o el peligro que detiene cualquier intento de comprensión de las diferencias culturales. Y este no es un movimiento del sentido común o de la vanguardia literaria o de la vulgata que se publica en los medios en la década del 40, sino algo que está en el corazón mismo del discurso criminológico y, por lo tanto, del tratado de etnología criminal que escribe Ortiz.

El artículo de Wallace explica el mundo caribeño para el lector civilizado haciendo el gesto inicial de la etnología y deslizándose de inmediato hacia el vocabulario médico que patologiza y criminaliza la diferencia. El texto señala que la magia negra y el vudú no son sólo diferencias culturales sino actividades peligrosas -tal como lo eran en Ortiz-que lindan con lo delictivo. En Ortiz, la brujería llevaba en sí el germen del delito y de hecho, Los negros brujos está organizado alrededor de un caso ejemplar que permite la generalización: el supuesto asesinato de una niña blanca en manos de cuatro hechiceros que requerían de sus vísceras para curar una enfermedad. Con Wallace avanzamos un paso más allá y la criminalidad excede el asesinato común porque de lo que se trata aquí es de matar incluso al muerto y convertirlo en un zombie. Lo que denuncia Wallace, entonces, lo que descubrimos luego de leer "I Walked with a Zombie", es que "the mysterious arts of the black people of Haiti have caused dead persons to rise from their graves and enter a soulless existence as slaves, their bodies moving around without any individual intelligence” (98).

La otredad que la etnología criminal presenta, se literaliza por completo en su versión mediática: se trata de un otro absoluto, que excede el terreno de lo criminal y por lo tanto lo humano. El problema de la magia negra ya no culmina en el asesinato sino que avanza hasta la producción de lo impensable: el muertovivo. Si la etnología trata de poner en suspenso el valor que se distribuye sobre las diferencias, la criminología repone un discurso sustentado en la enfermedad y la salud, en la normalidad y la criminalidad que es lo que recupera Wallace aquí. Si la etnología borronea la figura del monstruo, la criminología entrega el vocabulario que funcionará como origen de una nueva configuración monstruosa construida sobre el lenguaje médico. Se trata de un verdadero monstruo biopolítico, en diálogo directo con las categorías vinculadas a la vida, un monstruo que ya no surge como aberración o como pura alteridad sino como resultado de un diálogo entre lo sano y lo enfermo, entre los "tumores sociales" y los elementos saludables de la nación o, como lo literaliza Wallace aquí, entre el orden de los vivos y el universo de los muertos. Este nuevo monstruo, resultado de la hibridez entre etnología y patologización, entre cercanía y exotismo, representa un peligro absoluto. Es literalmente una enfermedad encarnada contra la cual toda violencia resulta legítima, en la medida en que ni siquiera opera en el mundo de los vivos, sino en el espacio de la desacralización de la muerte. 
Lo que Wallace se propone es arrancar al zombi del espacio de la ficción y proclamar su existencia real y es evidente que "I Walked with a Zombie" cumple eficazmente con el objetivo de su autora. ¿Qué es exactamente un zombi? "They are not ghosts, not phantom wraiths but flesh and blood bodies which are dead, yet can move, walk, work and sometimes even speak" (99). Los zombis no pertenecen al mundo de los fantasmas ni al mundo incorpóreo del espíritu, sino que son pura corporalidad definida a partir de tres acciones principales: moverse, caminar, trabajar e incluso a veces hablar.

Más allá de las intenciones de Wallace, el texto nos permite recortar una figura perfectamente contorneada por la historia: la del esclavo, la de alguien que según el Code Noir -en vigencia en Haití hasta la revuelta de 1791- no se conceptualizaba como un sujeto sino como una propiedad susceptible de ser vendida. La magia negra, no sólo perturba al cadáver y lo arranca de su reposo, sino que al hacerlo moverse, caminar y trabajar lo coloca "in the fields, working with the negroe slaves" (100). ${ }^{2}$ Entre lo vivo y lo muerto, entre el sujeto y el objeto, no hay mejor definición del esclavo que la de una pura corporalidad destinada al trabajo. Por otra parte, lo inquietante del zombie es que actúa, que trabaja en contra de su voluntad o sencillamente que carece de ella, del mismo modo que carece de conciencia de su situación. Por eso, lo que se pone en juego para redimirlo de su condición es precisamente la muerte. Para liberar al zombie hay que eliminarlo como tal, dándole sal para permitirle estar "dead for good”. El zombie cifra, con los géneros de la cultura masiva, la paradoja de la libertad como aquello que no se posee sino luego de haber puesto en riesgo la vida. Esta idea de que la libertad es aquello que se obtiene sólo luego de estar dispuesto a morir antes que carecer de ella está en el centro de los debates filosóficos de fines del XVIII y principios del xIX y, por supuesto, en el corazón mismo del pensamiento hegeliano. Sin embargo, como señala Frederick Douglass, embajador de los Estados Unidos en Haití en 1899, el esclavo prefiere activamente la posibilidad de morir a la condición inhumana a la que es sometido en los campos. ${ }^{3}$ La elección entre la libertad o muerte que metafóricamente guía

\footnotetext{
2 El relato de Wallace está compuesto por una serie de ejemplos o de micro-relatos sin ubicación histórica precisa. La mención a los “negroe slaves” ubicaría estos episodios antes de la abolición de la esclavitud en la isla, en 1794. Sin embargo, en la primera línea del artículo, Wallace menciona a Haití como la tierra de "Christophe, the Black Napoleon, rose to world fame as the Negro emperor", por lo tanto, todo lo narrado ocurriría, al menos, después de su reinado en 1811. Por otra parte, la crónica se cierra con una mención a la respuesta del gobierno y al presente en el que enuncia la cronista, con lo cual los relatos podrían ocurrir también en el siglo xx. Volveré más adelante sobre el modo en que funciona el anacronismo o la ambigüedad en Wallace.

3 Para una relación entre el debate filosófico que se da a principios del xix alrededor del concepto de libertad y su vínculo con el esclavismo, véase Susan Buck Morss, especialmente los apartados 7 y 8.
} 
la revolución francesa y el debate filosófico de principios del siglo xIX se vuelve literal en el caso del zombi, del mismo modo que lo fue para el esclavo.

Si bien el zombi cifra la figura histórica del esclavo y llama la atención sobre la dimensión eminentemente biopolítica de ese fenómeno, lo que lo vuelve una figura incluso más interesante y más compleja es el hecho de que, en realidad, el zombi no es el negro esclavo, sino un sujeto blanco convertido en esclavo, gracias a la magia negra. En el centro del artículo de Wallace, se despliegan -tal como ocurre con el ensayo de etnología criminal de Ortiz o con casi toda la producción criminológica-los casos, los ejemplos que ilustran y fundamentan la generalización "teórica". Uno de esos casos es el de George MacDonough, que tiene un amorío con Gramercie, "a dusky native girl”, un amorío que dura "only until a white girl fell in love with him”. George contrae matrimonio con Dorothy Wilson y cuando Dorothy muere, la vengativa Gramercie recurre al vudú para transformarla en una zombi. Lo terrible del relato no es la conversión en zombi, que sólo se menciona al pasar, sino el desenlace de la historia. Al descubrir que el cadáver de Dorothy no está en su tumba, George sale a buscarla y la descubre absolutamente fuera de lugar: no sólo fuera del cementerio sino también en un lugar que, en caso de estar viva, también sería inadecuado. "For in the fields, working with the negro slaves, was the corpse of George MacDonough’s wife!”, señala con escándalo Wallace. La escena continúa y lo escandaloso se vuelve siniestro en el momento en que "he went up to her, but her blue eyes stared at him blankly. They showed no recognition of her husband".

El regreso del muerto a la vida no es un retorno de lo mismo, sino de la imposibilidad de volver a las cosas tal y como estaban. Adiferencia del mito cristiano de la resurrección que implica el regreso a la vida, con las características de la vida y, por lo tanto, supone un regreso sin modificaciones -y aquí el gran ejemplo no sólo es Jesucristo, sino Lázaro que, luego de permanecer algunos días muerto, vuelve a la vida tal y como estaba antes de morir-, el zombi es como el vampiro: el regreso a la vida jamás es el regreso de lo exactamente igual, sino precisamente el universo de lo inquietante, el trastorno de lo familiar.

Cuando Napoleón envía a sus tropas a Santo Domingo para reestablecer el Code Noir, los soldados, "al escuchar a ex esclavos cantar la Marsellesa se preguntaban a viva voz si no estaban peleando para el lado equivocado” (Buck Morss 103). La imagen de esta mujer blanca en un espacio al que no pertenecería -el campo-, haciendo algo que no debería -trabajando-, siendo esclava cuando debería ser ama, trabajando cuando está muerta, no es tanto un relato de lo absolutamente extraño, sino del desarreglo que provoca la mezcla y el desorden. Al igual que el relato del ejército napoleónico, la historia del zombi no es una historia de terror, no implica la irrupción de aquello que es totalmente ajeno ni la alteración del mundo narrada 
como catástrofe impensable. Son relatos que convocan a lo siniestro y declaran la precariedad de un estado de cosas que está acechado por la transformación -sin celebrarla pero tampoco declararla escandalosamente impensable-, esto es: señalan el peligro del enrarecimiento del mundo conocido.

\section{Monstruosidad, LEGALIDAD y UTOPÍA}

¿Qué es exactamente un monstruo? Dos condiciones parecen ser necesarias para que exista un monstruo: la anomalía y el peligro. El monstruo implica un irregularidad, una excepcionalidad, algo que representa lo imprevisible asaltando el estado de las cosas. Sin embargo, lo puramente diferente no es monstruoso; el monstruo convoca también un estado de peligro, es algo que no sólo interrumpe el estado de cosas sino que además lo amenaza. La monstruosidad del zombi parece cumplir con ambas condiciones, implica una alteración y también un ataque al orden que divide dos órdenes diferenciados. Sin embargo, lo monstruoso del zombi no reside tanto en su pura alteridad como en todo lo que tiene de conocido. Es el amo blanco que actúa como esclavo negro, es el muerto que, lejos de permanecer en el más allá, vuelve a perturbar el orden de los vivos, para confundir el límite que separa a unos y otros. Es por eso que lo peligroso del zombi no es tanto su accionar, lo que pueda hacerles a los otros, sino su existencia misma que parece recordarnos que el límite que distingue vivos y muertos, amos y esclavos es bastante precario y susceptible de ser alterado en cualquier momento.

El zombi podría pensarse como la imagen misma del monstruo humano: diferente, es decir monstruoso y semejante, es decir humano. Se trata de una figura, dice Michel Foucault, “cuyo marco de referencia es la ley. Noción jurídica, entonces, pero en sentido amplio ya que en ella se trata no sólo de leyes de la sociedad sino también de leyes de la naturaleza” (42). El monstruo humano plantea el problema de la regularidad jurídica, dice Foucault, la pregunta por qué es lo que cumple con las leyes sociales y naturales y qué se presenta como un atentado a ambas. Por eso, el artículo de Wallace comienza con una referencia explícita al código penal. "Here is the law, found in Article 249 of the Criminal Code of Haiti", dice Wallace al citar el código criminal. El artículo 249 dice "it shall be qualified as attempted murder the employment which may be made against any person of substances which, without causing death, produce a lethargic coma more or less prolonged. If, after the administering of such substances, the person has been buried, the act shall be considered murder no matter what result follows” (95). Según la interpretación de Wallace el código legaliza -y de este modo reconoce- la eficacia de la magia negra y la figura del zombi. “That law was put on the books”, argumenta Wallace, "because it has been proved that time and again the mysterious arts of the black 
people of Haiti have caused dead persons to rise from their graves and enter a soulless existence as slaves, their bodies moving about without any individual intelligence” (95). El código penal no legisla directamente sobre el zombi, no prohíbe que alguien ejerza la magia para volver a la vida a un muerto ni penaliza al muerto que revive; lo que la ley parece legislar es el uso de sustancias que hacen que un vivo parezca muerto y de este modo, busca extender la definición de asesinato o de intento de asesinato en tanto se incluye la administración de sustancias que puedan llevar a enterrar a alguien vivo considerándolo muerto, "no matter what result follows” (95). Y precisamente por eso, hay cierta sagacidad en el vínculo que propone Wallace entre esta legislación y la creencia en el zombi. Aunque se trata de un gesto inverso -el vivo que parece muerto-, el código rige sobre el mismo problema que se instala alrededor de la figura del zombi que estando muerto parece vivo. El zombie es un muerto que no regresa a la vida porque no resucita, es el que regresa con los atributos del cadáver para irrumpir en el mundo de los vivos. No es el resucitado, sino el muerto-vivo, el que corrompe la diferencia entre lo vivo y lo muerto. Por eso, la mención al código penal -si bien no parece ser una prueba de la existencia de los zombis como pretende Wallace- penaliza la confusión de lo vivo y lo muerto, y al mismo tiempo señala que el zombi, en tanto monstruo humano, convoca el problema de la trasgresión de la ley; ley social en tanto toca los límites y la definición de la criminalidad y del asesinato, y ley natural en tanto implica la hibridación de lo vivo y lo muerto. ${ }^{4}$

El zombi define una nueva tipología de lo monstruoso, en tanto implica un peligro -como todo monstruo- aunque no se constituye a partir de la pura diferencia, tal como ocurre con los monstruos clásicos como el dragón, el basilisco o la Quimera,

\footnotetext{
4 De hecho, la relación entre esta legislación y la figura del zombie es un gesto recurrente. El antropólogo suizo Alfred Métraux desarolla un intenso trabajo de campo en Haití a fines de la década del 40 y estudia la historia y la práctica del vudú y sus vínculos con el catolicismo y el lugar que desempeña en el desarrollo de la revolución y la vida política de la isla. En Voodoo in Haiti, el libro que publica en 1959, repite e incluso explicita la conexión entre magia y delito que propone Wallace en su artículo periodístico. Dice Métraux: “Article 246 of the old Penal Code relates to zombies as follows: 'Also to be termed intention to kill, by poisoning, is that use of substances whereby a person is not killed but reduced to a state of lethargy, more or less prolonged, and this without regard to the manner in which the substances were used or what were their results. If, following the state of lethargy the person is buried, then the attempt will be termed murder'” (281). El zombi convoca este vínculo entre la transgresión de la ley natural que separa lo vivo de lo muerto y la ley positiva que prohíbe el asesinato, aunque simultáneamente confunde la clara distinción legal entre víctima y victimario. Es el mago o el que “crea” al zombi el que estaría transgrediendo la ley y el zombi sería algo así como la víctima. Sin embargo, en tanto resultado, imagen misma de la transgresión a las distintas legalidades, el zombi aparece como metáfora o figura paradigmática de la trasgresión. Ocurre con él lo mismo que ocurre con el gran monstruo moderno, la criatura creada por Frankenstein: sin responsabilidad por su existencia, la criatura aparece menos como una víctima de su creador y más como la encarnación misma de la transgresión a la ley, científica, natural, ética, etc.
} 
sino a partir de una torción dentro de lo humano. Sin embargo, esa torción tampoco convoca al mundo animal como lo hacen las figuras monstruosas clásicas -desde el Minotauro hasta el hombre-lobo-, sino de una contaminación entre lo vivo y lo muerto. ${ }^{5}$ La problemática del zombie -y no me refiero aquí sólo a la figura del zombi sino a la relación entre el zombi y el brujo o el mago que es condición de su existencia-es un desenlace lógico del nudo que, desde comienzos de siglo, empieza a establecerse entre discurso médico y discurso legal. La medicina se transforma así en el relato maestro que explica la transgresión a la ley positiva, en términos de atentado a las leyes naturales o físicas, al mismo tiempo que medicaliza toda diferencia cultural, racial, sexual.

El libro de etnología criminal que Fernando Ortiz publica en 1906, en el contexto de la reciente independencia de Cuba, constituye una genealogía racial que, focalizándose en Cuba, se propone como explicación caribeña, y al mismo tiempo, un programa acerca de cómo resolver las tensiones entre las diferentes razas y culturas que definen la identidad caribeña. En un intento por desarticular los mecanismos de legitimación de la violencia racial y de las exclusiones políticas, Ortiz postula una serie de hipótesis etnológicas que cuestionan la figura monstruosa del enemigo y proponen una política paternalista que apuesta por la hibridez. Sin embargo, en su inflexión criminológica, el vocabulario médico de Los negros brujos liga la cultura negra con la criminalidad y con las “capas cancerosas” de la sociedad. Si Ortiz intenta borrar la imagen monstruosa del otro, lo que una zona de Los negros brujos produce es un monstruo nuevo que crece a la sombra de la patologización. Con Los negros brujos se inicia esta nueva configuración monstruosa construida

5 En 1943, Jacques Tourneur estrena I Walked with a Zombie, una película basada en el texto de Inez Wallace y en Jane Eyre de Charlotte Brontë (el director señala reiteradamente este hecho, aunque no hay mención a la novela en los créditos del film). La película es uno de los hitos del cine de horror de la década del 40, junto con la película anterior y la siguiente del mismo director: Cat People, estrenada en 1942 -con guión de DeWitt Bodeen- y Leopard Man, basada en Black Alibi, la novela de Cornell Woolrich, y estrenada un mes después de I Walked with a Zombie. En los tres filmes de Tourneur, el horror está vinculado a la transformación -en pantera, en leopardo o en zombi-; sin embargo, la película basada en el artículo de Wallace señala el lugar esencial que ocupa la magia vudú en el universo del horror: por un lado, reemplaza al monstruo más recurrente -el que surge de la cruza entre lo humano y lo animal-y, por otra parte, recupera la tradición del horror que trabaja a partir de la figura del muerto que regresa sin volver a la vida totalmente y que se liga a la figura del vampiro. De hecho, luego de producir de estas tres películas de Tourneur, Val Lewton produce The Isle of the Dead, una película estrenada en 1945, con guión de Ardel Wray, que también había trabajado en el guión de Leopard Man y I Walked with a Zombie. The Isle of the Dead transcurre durante la guerra y narra la historia de un grupo que está atrapado en una isla griega debido a una plaga que los obliga a hacer cuarentena. La película reúne ciertas figuras clásicas del relato de terror: la plaga y el encierro, pero las sitúa en el contexto de la guerra mundial y mezcla la tradición del personaje de Stoker con esta figura del muerto-vivo, que viene del contexto de la magia negra y de los zombis. 
por el lenguaje médico -entre lo sano y lo enfermo, entre los "tumores sociales" y los elementos saludables de la nación- que encuentra su punto culminante en la figura del zombi.

En la década del 40, las hipótesis etnológicas de Ortiz constituyen la doxa del discurso sobre la diferencia racial y también resuenan en el corazón de la nueva vanguardia llamada primitivista que reúne a Lydia Cabrera, a Wilfredo Lam y a tantos otros artistas y escritores. La vanguardia minorista cubana y el llamado "movimiento negrista” explícitamente desecha el vocabulario médico y los mecanismos de patologización de Los negros brujos. En Los cuentos negros de Cuba, Lydia Cabrera refuncionaliza la figura del monstruo para proponer una refundación cultural. Ya no hay una otredad que contemplar y explicar; el mundo lucumí toma la escena para reescribir el imaginario cultural caribeño y proponer nuevos mitos de origen, revisiones de la historia colonial y reescrituras de la tradición literaria y nuevos modos de pensar la colectividad y el funcionamiento político.

No quiero adentrarme aquí en el análisis de los cuentos de Cabrera. Sólo me interesa marcar, por contraste, ciertas características que funcionan como elementos centrales de un programa político y estético que se propone desactivar el vínculo entre crimen y anomalía y que funcionan, por oposición, como claves de lectura de la figura del zombi. Cabrera recupera este poder disruptivo e híbrido asociado a la magia, pero se escapa por completo del vocabulario médico y reformula el modo de postular la pregunta por la ley. Uno de sus cuentos, "Bergantino Bergantín”, narra la historia de un toro que se convierte en rey. Aunque convoque la figura del Minotauro, el personaje no es exactamente un monstruo, la hibridez entre humanidad y animalidad no está narrada en clave amenazante. ${ }^{6} \mathrm{Y}$ sin embargo, el personaje y el cuento mismo convocan la pregunta por la ley. Dice el relato:

todos los años le nacía un hijo en Dingadingá; pero no le bastaba una mujer, ni cinco, ni diez y declaró, en consecuencia, que todas las mujeres de Cocozumba le pertenecían por derecho propio. Algunas protestas se levantaron, más o menos violentas, aquí y allá. Para evitar que a ellas se sumaran otras, cundiendo el mal ejemplo, mandó matar-y él mismo se constituyó en verdugo-a todos los hombres

\footnotetext{
6 De hecho, las continuas metamorfosis que ocurren en todos los relatos están marcadas por un fuerte componente lúdico y humorístico. En este mismo cuento, la Lombriz se casa con la princesa y reina durante varios años. Al morir le cede su reino y su mujer al Toro, su antiguo esclavo. La muerte de la Lombriz involucra un juego de transformaciones porque, al morir, la Lombriz se transforma en lombriz ya que antes era un hombre, aunque tuviera el nombre de este animal. Dice el cuento: "tan pronto Lombriz desapareció por el agujero de cualquier tragante, reduciéndose de tamaño y cobrando la forma que en justicia le correspondía y tal cual hoy se le conoce y se le evita -antes había sido un hombrecito blanco, de facciones menudas, labios finos, amargos, un bigotito, calvo, de pecho abultado, las piernas y los brazos cortos” (Cuentos negros de Cuba 42).
} 
del reino, sin exceptuar sus propios hijos. En lo adelante, cada vez que una de sus innumerables concubinas daba a luz un varón, le afeaba su conducta, la castigaba severamente y, por último, degollaba a la criatura. (Cuentos negros de Cuba 43)

Con esta suerte de fábula que transcurre en el reino de Dingadingá y que reúne al Minotauro con el relato freudiano de la horda primitiva, Cabrera se convoca la pregunta por la ley: ya no sólo la ley natural o la ley positiva, sino también, la ley que rige lo político. La pregunta que formula Wallace es, entonces, exactamente la inversa a la que propone la vanguardia negrista. Con Cabrera, por ejemplo, se trata de pensar que la fundación de lo humano y de una legalidad que lo defina son instancias que hablan más de una simultaneidad que de una sucesión temporal y lógica. Se trata también de pensar que el mito y la magia, lejos de ser lo excluido de lo social, desempeñan un lugar particular en la fundación de una colectividad.

Así, Cabrera recupera la mirada etnológica de Ortiz pero la despoja del narrador en primera persona y del vocabulario médico. Si Ortiz dice que estos textos hablan de la colaboración entre "el folklore negro y su traductora blanca” (32), para Cabrera esa colaboración implica su borradura. Los cuentos jamás se introducen con un marco que señale que alguien contó este relato o que alguien le contó a un narrador o narradora este relato. El mito, la magia y el folklore ocupan la escena, sin una voz que regularice o que señale una racionalidad que se opondría a esta mitología. ${ }^{7}$ Y lo

7 Wallace y Cabrera dicen estar movidas por la misma intención de colocarse en un lugar de testigo, de observador que no participa y narra con “objetividad” lo que aparece frente a sus ojos. Wallace recupera una serie de testimonios que darían cuenta de la existencia de los zombis, Cabrera también asume este lugar de "copista" del material que tendrá su firma. Tal como explícitamente declara en El monte, "ha sido mi propósito ofrecer a los especialistas, con toda modestia y la mayor fidelidad, un material que no ha pasado por el filtro peligroso de la interpretación, y de enfrentarlos con los documentos vivos que he tenido la suerte de encontrar" (8). Lo que Cabrera supuestamente transcribe son relatos, ficciones que se reconocen como tales en el momento en que se describen y circulan como "cuentos"; en Wallace también se transcriben ciertos testimonios que documentan la existencia de los zombis. En Wallace el valor de "verdad" de esos relatos descansa en la supuesta existencia fáctica de ese objeto; en el caso de los relatos de Cabrera lo que se invoca es otro estatuto de verdad que apunta al modo en que funcionan los relatos -no sólo los cuentos de Cabrera, sino todo relato, incluído el de Wallace-, lo que se invoca es la potencia de un discurso capaz de producir modelos de inteligibilidad, valores y modos de leer e interpretar el mundo. La "verdad" de un relato, nos dicen los textos de Cabrera, no reside en la ingenuidad de creer que lo narrado pertenece al orden de los hechos, sino que son las palabras las que existen y tienen efectos sobre el mundo que narran. Por eso, los Cuentos negros de Cuba ensayan relatos de origen que explican las diferencias raciales, la fundación de la ley o del lenguaje, desde una perspectiva que no tomaría la razón científica como parámetro central, sino el mito y la magia. Sin embargo, Cabrera insiste incluso más que Wallace en su carácter de mera transcriptora: "Me he limitado rigurosamente a consignar con absoluta fidelidad y sin prejuicio lo que he oído y lo que he visto... [el valor de estos relatos] consiste exclusivamente en la parte tan directa que han tomado en él los mismos negros. Son ellos los verdaderos autores" (El monte 8 y 10, el destacado es mío). Si ambas autoras dicen sólo transcribir, Wallace elige reforzar el 
mismo ocurre con el vocabulario médico y los patrones de sanidad y enfermedad que, a partir de la criminología, conectan la patología con la ilegalidad. Casi podría decirse que la mezcla entre medicina, discurso legal y etnológico se condensa en el cuerpo del zombie y en su peligrosidad que es, al mismo tiempo, una amenaza al campo de la vida y al campo de la ley.

Si los relatos de Cabrera se presentan como el despliegue de una cosmovisión que ataca el lugar privilegiado de la razón occidental y la reemplaza por la magia, en Wallace se trata de denunciar la peligrosidad de la magia y de su capacidad de alterar el orden de la vida y el orden de la ley. Y tal vez aquí el texto de Wallace alcanza su momento más productivo. Donde Cabrera parece omitir el conflicto o dar por ganada, en el campo de la ficción, una batalla entre razón y magia, Wallace recentraliza el conflicto: el artículo mismo se escribe para resaltar la peligrosidad de la magia negra y como un llamado a combatirla. En este contexto, la figura del zombie es la figura ideológica por excelencia. Como propone el texto de Wallace, "form mysterious Haiti come other stories of the occult; mystic tales of voodoo, black magic, spells, haunting, curses and animal magnetism” (99). El zombi se inscribe en el juego de la ideología, entre lo que está oculto y lo que se oculta, entre lo que se intenta enterrar o silenciar y sin embargo resurge una y otra vez. La figura del zombi es ideológica porque naturaliza un orden de cosas al señalar el peligro de que ese orden se vea alterado. Si la magia negra es peligrosa es precisamente porque sería capaz de alterar cierto estado "natural” de cosas en el cual, del mismo modo que los vivos están en la tierra y los muertos bajo ella, los negros están en los campos y los blancos fuera de allí. El relato de zombis produce una equivalencia entre el lugar natural de los cuerpos vivos y muertos y el lugar natural de los cuerpos en el circuito del trabajo. Así, lo que el relato dice es que no hay nada perturbador en la esclavitud real ni en el lugar que ocupa el esclavo negro en los campos pero sí en la alteración de ese orden. Precisamente por eso, el peligro de la magia negra reside en su capacidad de alterar e invertir aquello que es natural y dado.

El zombi es una figura ideológica porque funciona a partir de los dos momentos de la ideología: a partir de la inversión y el ocultamiento, pero también poniendo en escena algo del orden de la verdad. El zombi invierte, en términos imaginarios, la verdad de lo real. Por una parte oculta el carácter histórico de las relaciones de explotación y las presenta como naturales; por otra parte, entrega el vocabulario

lugar del Yo que registra lo narrado; Cabrera en cambio opta por borrarse como autora para entregarle la autoría de sus textos a un grupo, a una colectividad. Aunque Wallace no pueda decir lo mismo, aunque su firma y la primera persona de la periodista-etnóloga garantice la verdad del "testimonio" que ofrece la crónica, Wallace también transcribe una serie de relatos que no son de su autoría. Si Cabrera escribe los cuentos negros de Cuba, Wallace narra, en clave de crónica siniestra, la mitología blanca que produce Haití. 
perfecto para narrarlas. Al omitir un estado de cosas real para describir el pánico que produciría su alteración mágica, Wallace construye una bioeconomía que describe las relaciones de dominación como una muerte en vida, a los sujetos como cadáveres vivientes, como cuerpos arrancados de lugar y expropiados de la voluntad y de la palabra. El artículo de Wallace, que no se detiene ni un segundo en el esclavo negro o en la figura del trabajador explotado en los campos, se explaya sobre la figura fantasmática del zombie, que si existiera sería la cifra perfecta de eso que realmente existe y se llama esclavitud o relaciones de dominación. ${ }^{8}$

Asumiendo un lenguaje de la mezcla en el que las palabras mismas sufren transformaciones genéricas y oscilaciones constantes entre la antropología y la ficción literaria, Cabrera experimenta con los límites de lo pensable para proponer una verdadera utopía política, en la que la magia y las identidades alteradas encarnan la utopía política. El texto de Wallace es el reverso perfecto de esa utopía: es el relato del esclavo liberado, narrado como la pesadilla de los amos. Por eso, tiene razón Inez Wallace cuando señala que el zombi no es una leyenda ni una metáfora. Tal vez no haya zombis, tal vez la magia negra no sea tan poderosa como para transformar a los cadáveres en obedientes trabajadores. Sin embargo, ¿cómo no temer al vudú si fue un elemento clave para cohesionar a los esclavos en lo que se transformaría en la gran revolución haitiana? ¿Cómo no temer a la alteración mágica o revolucionaria de un estado natural de cosas que ordena la economía de los cuerpos? El zombi es un cuerpo fuera de lugar y como tal convoca menos al horror y más a la inestabilidad de lo siniestro, al desamparo que produce una

\footnotetext{
8 Si los relatos de Cabrera trabajan en contra de la diferencia racial -y de algún modo proponen una utopía en la que la pertenencia a un grupo racial u otro no importa o es absolutamente borroneada o un mundo en el que no hay un grupo racial que funciona como "término no marcado" y otro que sí-, la crónica de Wallace insiste en remarcar esa diferencia. En "I Walked with a Zombie”, los personajes se identifican como blanco o negros y cumplen funciones específicas de acuerdo a esta diferencia racial: la mujer negra es la amante y la blanca es la esposa, el hombre negro es el brujo y el blanco la víctima de su brujería. Sin embargo, el texto de Wallace no distribuye roles en un mundo nebuloso sino en un espacio específico: "the field". Probablemente sin que su autora lo quiera, el relato de Wallace pone en primer lugar el trabajo y la dimensión económica de la explotación esclavista. Así, la esclavitud deja de ser una relación de dominio "puramente racial" para especificarse como el modelo para pensar cualquier relación de dominio. En este sentido, el anacronismo de Wallace puede recuperarse como crítica política. Por una parte, las historias de la crónica transcurren en una suerte de "pasado eterno" - en el que quedarían estancados los lugares mágicos y primitivos como Haití- donde habría amos y esclavos y en el que la esclavitud sería parte del circuito económico. Por otra parte, el hecho de que se postule un presente en el que la figura del esclavo o del zombie trabajando en los campos como esclavo, redefine la esclavitud no como un sistema de explotación fechado históricamente sino como clave para pensar las relaciones de explotación en el capitalismo moderno. Del mismo modo que Franz Fanon recupera la dialéctica del amo y del esclavo para pensar las relaciones de sujeción del capital, George A. Romero relee la figura del zombie explícitamente como cifra de los efectos del fetichismo de la mercancía y de la sociedad de consumo.
} 
revolución cuando da vuelta a las cosas, borronea las diferencias y deshace la distinción entre los vivos y los muertos, entre los amos y los esclavos, entre el pasado, el presente y el futuro.

\section{BiBLIOGRAFÍA}

Buck Morss, Susan. Hegel y Haití. La dialéctica amo-esclavo: una interpretación revolucionaria. Fermín Rodríguez, trad. Buenos Aires: Norma, 2005.

Cabrera, Lydia. El monte. Miami: Colección de Chicherekú, 1971. Cuentos negros de Cuba. Barcelona: Icaria, 1989.

Foucault, Michel. Los anormales. Madrid: FCE, 2000.

Métraux, Alfred. Voodoo in Haiti. Nueva York: Schocken Books, 1972.

Ortiz, Fernando. “Prólogo a la primera edición castellana”. Lydia Cabrera, Cuentos negros de Cuba. Barcelona: Icaria, 1989.

Los negros brujos. Apuntes para una etnología criminal. Miami: Ediciones Universal, 1973.

Wallace, Inez. "I Walked with a Zombie”. Zombie! Stories of the Walking Dead. Peter Haining, ed. Londres: W.H. Allen, 1985. 95-102. 
1 